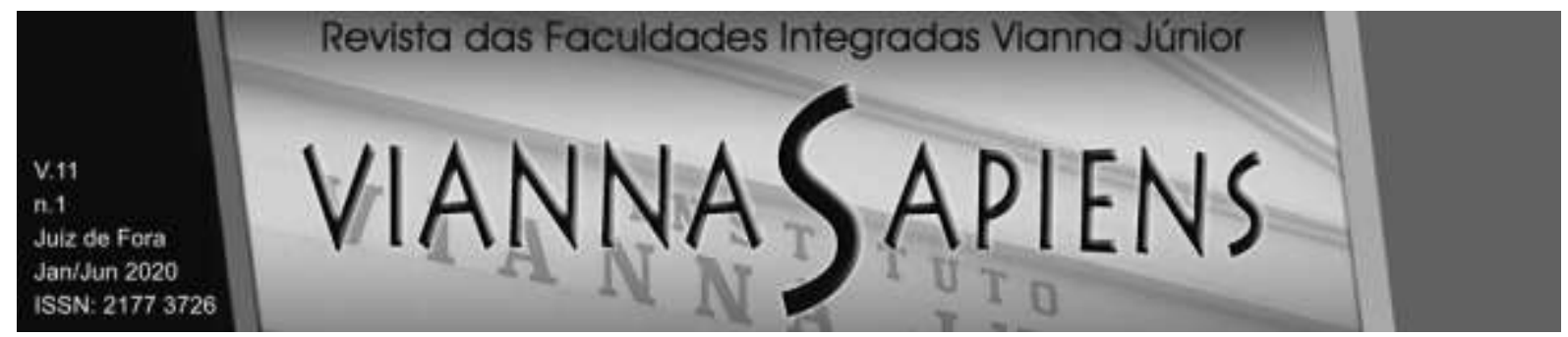

\title{
Atuação dos Procons nos casos de descumprimento das ofertas veiculadas nas plataformas de marketplace \\ DOI: 10.31994/rvs.v11i1.653
}

Fabrício Germano Alves ${ }^{1}$

Felipe Lucas Medeiros de Oliveira²

\section{RESUMO}

O presente texto trata da atuação realizada pelos Procons nos casos em que há descumprimento das ofertas que são veiculadas no comércio eletrônico, especialmente nas plataformas de marketplace. Em razão do aumento exponencial que esse tipo de relação jurídica de consumo teve nos últimos anos, torna-se um tema cada vez mais presente nas sociedades e assim urge a sua análise e discussão. Temse como objetivo geral a identificação das possibilidades e limites das atividades dos Procons no sentido de coibir o descumprimento das ofertas. Os procedimentos metodológicos consistem em pesquisa de natureza aplicada, com abordagem qualitativa e objetivo descritivo a partir de uma pesquisa bibliográfica e documental. Conclui-se que os Procons possuem legitimidade para, com fundamento no poder de polícia, atuar mediante a aplicação das sanções administrativas previstas no artigo 56

\footnotetext{
${ }^{1}$ Advogado. Especialista em Direito do Consumidor e Relações de Consumo (UNP). Especialista em Docência no Ensino Superior (FMU). Especialista em Direito Eletrônico (Estácio). Mestre em Direito (UFRN). Mestre e Doutor em Sociedad Democrática, Estado y Derecho pela Universidad del País Vasco / Euskal Herriko Unibertsitatea (UPV/EHU) - Espanha. Professor da Graduação e PósGraduação da Universidade Federal do Rio Grande do Norte (UFRN). Orcid: http://orcid.org/0000-00028230-0730

${ }^{2}$ Discente do Curso de Graduação em Direito do Centro de Ciências Sociais Aplicadas (CCSA) da Universidade Federal do Rio Grande do Norte (UFRN). Aluno bolsista de iniciação científica do projeto intitulado "Proteção jurídica do consumidor no comércio eletrônico (marketplace)". Orcid: https://orcid.org/0000-0003-3361-0115
} 


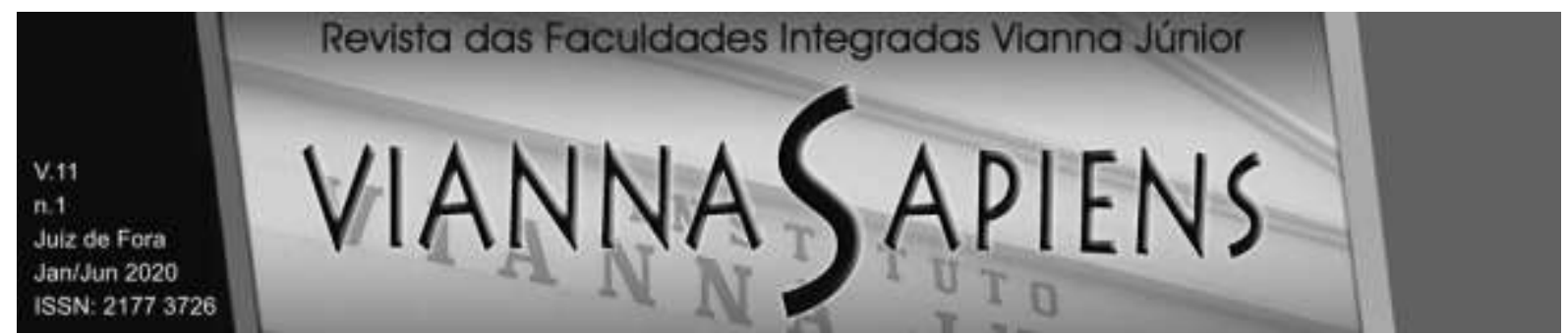

do Código de Defesa do Consumidor, responsabilizando solidariamente todos os fornecedores envolvidos na relação.

PALAVRAS-CHAVE: PROCON. OFERTA. MARKETPLACE. CONSUMIDOR.

\title{
Procons' acting in cases of noncompliance with the offers conveyed on marketplace platforms
}

\begin{abstract}
This text deals with the actions carried out by the Procons in cases where there is noncompliance with the offers that are conveyed in electronic commerce, especially in marketplace platforms. Due to the exponential increase that this type of legal consumption relationship has had in recent years, it becomes an increasingly present theme in societies and thus urges its analysis and discussion. The general objective is to identify the possibilities and limits of the Procons' activities in order to restrain the non-fulfillment of offers. The methodological procedures consist of applied research, with a qualitative and objective descriptive approach from a bibliographic and documentary research. It is concluded that the Procons have legitimacy, based on police power, to act by applying the administrative sanctions provided in article 56 of the Consumer Protection Code, holding jointly all suppliers involved in the relationship.
\end{abstract}

KEYWORDS: PROCON. OFFER. MARKETPLACE. CONSUMER. 


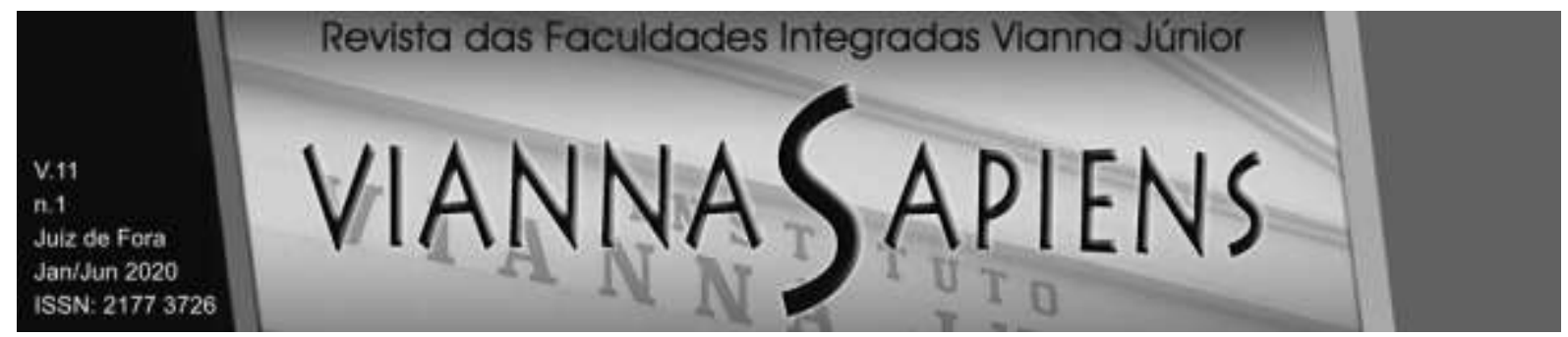

\section{INTRODUÇÃO}

O desenvolvimento de novas tecnologias e do avanço de sua acessibilidade permitem modificações substanciais nas relações jurídicas, especialmente as de comércio no âmbito civil e as de consumo. Com praticamente $80 \%$ da população do Brasil tendo acesso à internet (IBGE, 2019), é inevitável que muitas dessas relações ocorram no ambiente virtual, criando o contexto do chamado comércio eletrônico ( $e$ commerce).

Um dos modelos de negócio mediante os quais as relações de consumo ocorrem no comércio eletrônico é o marketplace (uma espécie de mercado virtual). Com o seu crescimento no país, aumentaram também as ofensas cometidas contra os consumidores. Este texto abordará a proteção que pode ser dada ao consumidor na esfera de atuação administrativa por parte dos órgãos públicos que detenham essa função dentre suas competências, com recorte à atuação dos PROCONs no combate ao descumprimento das ofertas.

A Constituição Federal de 1988 consagrou a "defesa do consumidor" como um dos direitos fundamentais (artigo $5^{\circ}$, inciso XXXII), e como um dos princípios da ordem econômica (artigo 170, inciso V). Ainda, no artigo 48 do Ato das Disposições Constitucionais Transitórias, instituiu uma ordem ao legislador no sentido de elaborar um Código de Defesa do Consumidor (CDC), que resultou na criação da Lei ํㅡㄴ 8.078/1990. Para que seja justificada, no entanto, a incidência do referido diploma legal, faz-se mister analisar as partes e o objeto das relações jurídicas, a fim de permitir que seja identificada a caracterização da natureza consumerista em cada caso concreto.

Considerando o amplo acesso à internet que se estabeleceu na década de 2010, o marketplace e as relações de consumo nele efetuadas ainda se mostram como "novidade" para muitas pessoas, que possuem poucas informações sobre seus direitos, sobre as obrigações dos fornecedores que atuam no marketplace, além das que devem ser assumidas pela própria plataforma em si. Essa falta de conhecimento é capaz de prejudicar o consumidor, v.g., quando este for lesado na relação, ou 


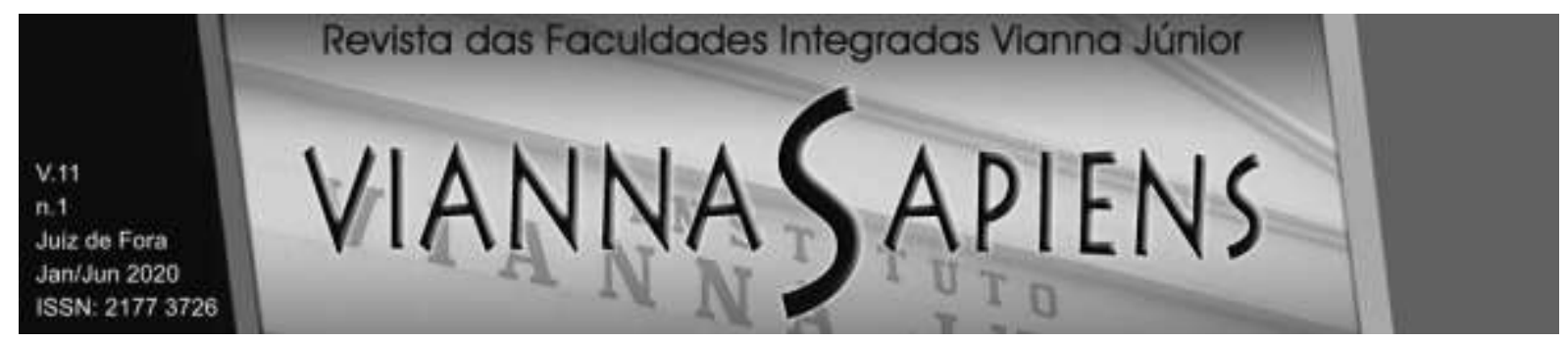

mesmo os próprios fornecedores, v.g., quando as relações deixam de ser efetivadas por fatores como a desconfiança e ausência de segurança.

Nesse contexto, é bastante salutar esclarecer como ocorre a atuação administrativa dos órgãos públicos na defesa do consumidor, tendo em vista que o Poder Judiciário (que também atua na defesa do consumidor) tem uma taxa de congestionamento (que é a relação entre processos sem solução e o total de processos tramitados no período de um ano) superior a 70\% (CNJ, 2019). Assim, fazse mister utilizar outras vias procedimentais para efetivação dos direitos previstos na legislação, como a via administrativa.

O presente trabalho tem como objetivo geral identificar as possibilidades e limites das atividades administrativas desenvolvidas pelos Procons no sentido de coibir o descumprimento das ofertas veiculadas nas plataformas de marketplace. Especificamente, buscar-se-á esclarecer como se configura a relação de consumo no ambiente do comércio eletrônico, especificamente nas plataformas de marketplace e como pode ser desenvolvida a atividade dos Procons no que diz respeito ao descumprimento de oferta pelos fornecedores que atuam nessas plataformas digitais.

Os procedimentos metodológicos utilizados consistem em pesquisa de natureza aplicada (voltada para a prática) com abordagem qualitativa e objetivo descritivo (em relação à relação de consumo e à atuação dos Procons), sendo desenvolvido a partir de pesquisa bibliográfica e documental.

Inicialmente, tratar-se-á da conceituação do comércio eletrônico, do marketplace e da relação jurídica de consumo, demostrando como se desenvolve a relação entre eles. Em seguida, será feita uma apresentação do conceito de oferta adotado pelo microssistema consumerista, apontando como pode ocorrer o seu descumprimento nas plataformas de marketplace. Por fim, serão discutidas as possibilidades de atuação dos Procons na seara administrativa para coibir esse tipo de prática e punir os fornecedores que dela se utilizam. 


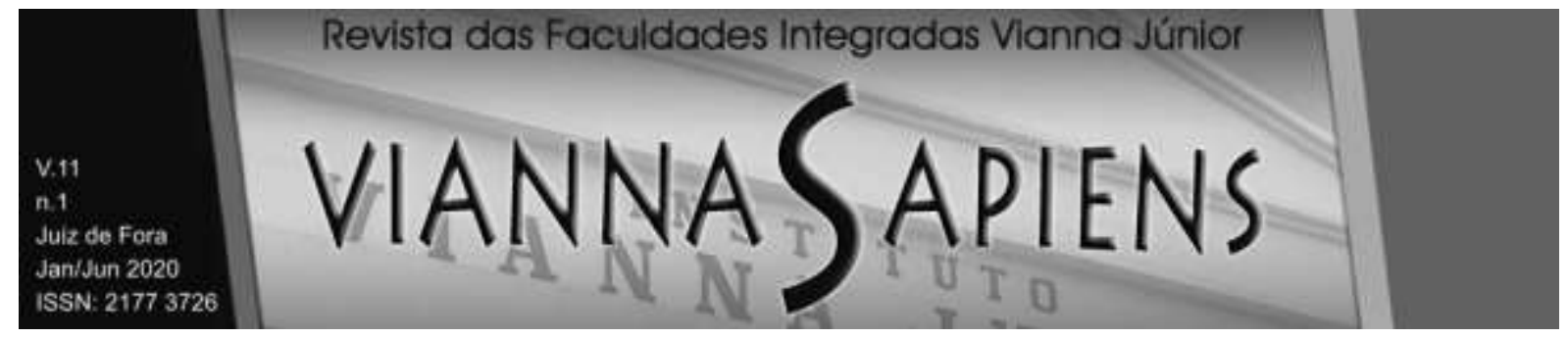

1 COMÉRCIO ONLINE, MARKETPLACE E RELAÇÃO DE CONSUMO

Antes de adentrar no estudo da atuação dos Procons nos casos de descumprimento de oferta nas plataformas de marketplace, é necessário que sejam abordados alguns conceitos iniciais. Primeiramente, há de se compreender o conceito de comércio eletrônico e como surge dentro deste o modelo de negócio intitulado marketplace. Além disso, é preciso explorar as ocasiões em que as relações comerciais firmadas nesses meios podem ser consideradas de consumo, sendo, portanto, regidas pelo Código de Defesa do Consumidor (CDC). A identificação dessas ocasiões é feita a partir do entendimento conceitual da relação jurídica de consumo.

\subsection{Comércio eletrônico e marketplace}

Quando se trata de comércio eletrônico (e-commerce), nele é englobada toda relação comercial que toma lugar no ambiente virtual, em contraponto às tradicionais relações que ocorrem física e diretamente (KLEE, 2014). O comércio eletrônico no Brasil começou a crescer rapidamente nos anos 2000 em decorrência da modernização e popularização dos meios de comunicação ${ }^{3}$, que favoreceram o desenvolvimento desse tipo de atividade econômica. Em 2001, o setor teve um faturamento de aproximadamente $\mathrm{R} \$ 549$ milhões de reais, saltando para $R \$ 14,8$ bilhões em 2010 e, finalmente, $R \$ 53,2$ bilhões em 2018, conforme os relatórios Webshoppers realizados pela empresa e-bit $(2005,2011,2019)^{4}$. Esse crescimento foi fruto das atividades de mais de 58 milhões de consumidores, o que equivale a mais de um quarto da população brasileira se utilizando do comércio eletrônico para adquirir e/ou utilizar produtos e serviços.

${ }^{3}$ De acordo com dados da Pesquisa Nacional de Amostra por Domicílios, realizada pelo Instituto Brasileiro de Geografia e Estatística (IBGE), no ano de 2003 pouco mais de 26 milhões de pessoas moravam em domicílios com pelo menos um microcomputador. Na pesquisa de 2008, este número aumentou para quase 61 milhões, um aumento de mais de $100 \%$ em 5 anos.

${ }^{4}$ Disponível em: https://www.ebit.com.br/webshoppers. Acesso em: 29 mar. 2020. 


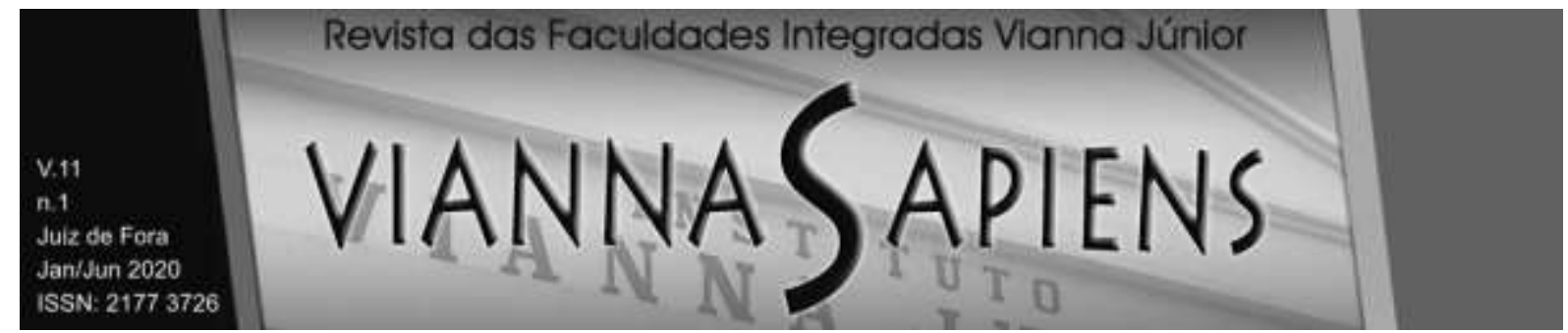

Ainda na análise dos referidos relatórios, é possível perceber que, por volta do ano 2010, iniciou-se o crescimento e a popularização, no Brasil, do modelo denominado de marketplace, que consiste em uma plataforma digital na qual vendedores oferecem seus produtos e serviços e os consumidores os buscam (WANG; ARCHER, 2007).

A prática, entretanto, não é recente, já na segunda metade da década de 1990, surgiram com grande força o E-Bay (www.ebay.com), nos Estados Unidos, e o MercadoLivre (www.mercadolivre.com.br), no Brasil e em outros países da América Latina. Estas plataformas operavam, essencialmente, no modelo de vendas C2C (consumer to consumer - consumidor para consumidor), segundo o qual as pessoas vendiam bens para outras pessoas, sem que houvesse relação de consumo por estarem ausentes os requisitos para a caracterização dos elementos subjetivos desta.

Entretanto, o modelo que causou uma grande expansão as plataformas de marketplace foi o B2C (business to consumer - fornecedor para consumidor) - como demonstram os relatórios WebShoppers ao destacar a participação do marketplace B2C nos números do e-commerce -, com fabricantes, produtores, lojistas e importadores oferecendo seus produtos e serviços aos consumidores em uma mesma plataforma digital. Esta construção assemelha-se ao que ocorre em centros comerciais físicos - os shopping centers (STARLING, 2018). O consumidor dirige-se ao local, no caso, uma página na web, e encontra diante de si diversas vitrines com mercadorias expostas. É possível, inclusive, encontrar produtos iguais vendidos por fornecedores diferentes, com condições de frete e preços distintos.

Este modelo (B2C), ao contrário daquele (C2C), é submetido ao regramento instituído pelo Código de Defesa do Consumidor, pois nos negócios nele efetuados é possível encontrar os elementos subjetivos, objetivos e causal ou finalístico, típicos da relação jurídica de consumo, que serão explorados a seguir. 


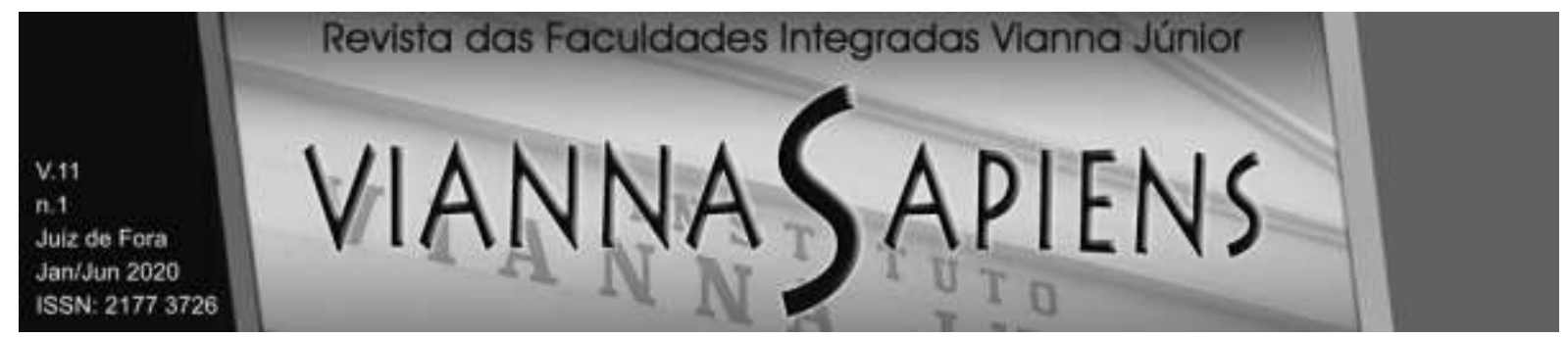

\subsection{Relação jurídica de consumo}

Dentro do seu elemento subjetivo, vê-se que existem dois polos nessa relação jurídica: um representado pelo fornecedor (que inclusive pode ser mais de um) e outro pelo consumidor. Aqueles que ofertam produtos ou serviços, disponibilizando-os no mercado de consumo, são fornecedores (MIRAGEM, 2019). Em adição, determina o artigo $3^{\circ}$ do Código de Defesa do Consumidor ${ }^{5}$, que o fornecedor pode ser qualquer pessoa, até mesmo os entes despersonalizados, desde que suas atividades resultem em sua inclusão e participação na cadeia de consumo.

Para a caracterização do fornecedor, é necessário também que exista habitualidade e profissionalismo - nos termos do que determina o artigo 966 do Código Civil, ao conceituar "empresário" - por parte do sujeito que comercializa o produto ou serviço. Desta forma, v.g., alguém que vende seu carro, após dele usufruir por anos, para comprar um novo, não seria caracterizado como fornecedor, diferentemente do caso de um estudante que também atua vendendo diariamente (habitualidade/profissionalismo) brigadeiros para auferir uma renda extra.

Quanto à figura do consumidor, algumas teorias têm se destinado a delimitar quem pode ser assim considerado, tomando como base o artigo $2^{\circ}$, caput da Lei $\mathrm{n}^{\circ}$ 8.078/1990, que determina que classifica como consumidor qualquer pessoa - sendo a relevância de fazer distinção entre pessoa física ou jurídica dependente da teoria adotada - que adquire ou utiliza produto ou serviço enquanto destinatário final. $O$ núcleo da discussão acerca das características que definem quem pode ser considerado consumidor é vislumbrado na expressão "destinatário final", que consubstancia o elemento causal ou finalístico.

A primeira é a teoria finalista, que classifica como consumidor aquele que é destinatário final fático, sendo o último na linha de transmissão do produto ou serviço, sem intenção de distribui-lo ou oferecê-lo a terceiro; e também destinatário final

\footnotetext{
${ }^{5}$ Art. $3^{\circ}$. Fornecedor é toda pessoa física ou jurídica, pública ou privada, nacional ou estrangeira, bem como os entes despersonalizados, que desenvolvem atividade de produção, montagem, criação, construção, transformação, importação, exportação, distribuição ou comercialização de produtos ou prestação de serviços.
} 


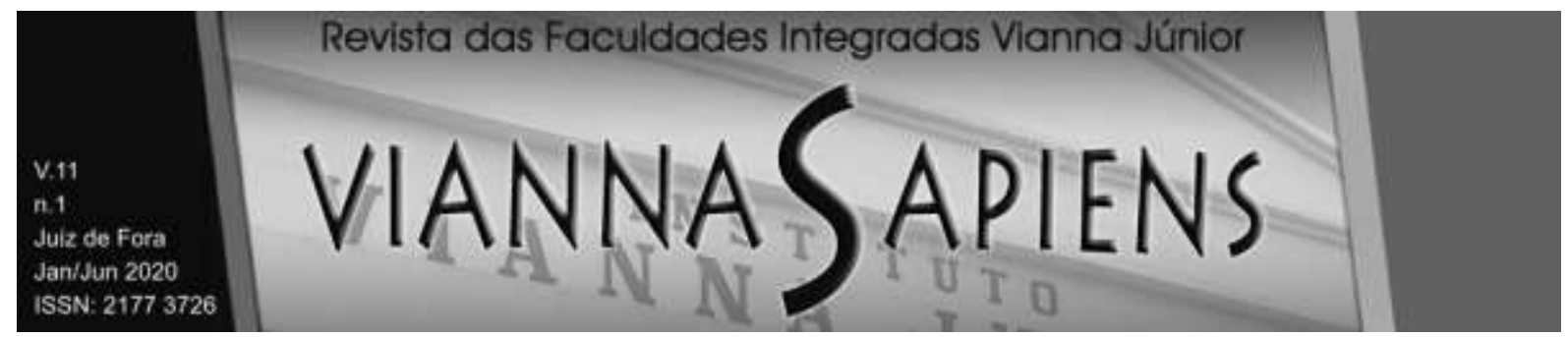

econômico, que não utiliza o produto ou serviço para obter vantagem econômica (TARTUCE, 2018). Para tal teoria, por exemplo, a pequena artesã que adquire para si uma máquina de costura para ser utilizada na confecção de seus produtos não seria tecnicamente consumidora, por obter do bem adquirido uma fonte de renda. Por casos como esse é que se reconhece a pouca proteção conferida por tal teoria, pois, segundo sua regência, não se protege alguns sujeitos que necessitam das garantias instituídas pelo Código de Defesa do Consumidor.

No outro polo de entendimento, surge a teoria maximalista, também chamada de objetiva, que classifica como destinatário final toda pessoa que contrata serviço, adquire ou utiliza produto para uso próprio, independentemente de destinação econômica atribuída a tal. Portanto, o único requisito para ser classificado como consumidor seria a destinação final fática do adquirente, interrompendo a cadeia de produção e circulação do bem ou serviço (SILVA, 2003). Com tal interpretação, protege-se como consumidor, v.g., desde a pessoa física que compra alimentos no mercado até o grande conglomerado industrial que adquire uma máquina para sua exploração econômica. Ao contrário da teoria finalista, que permite uma proteção limitada, a teoria maximalista é abrangente em demasia, sendo capaz de conferir um desbalanceamento da relação jurídica em favor de uma parte, que é por vezes até mais capaz de proteger os próprios interesses do que o próprio fornecedor.

Claudia Lima Marques (2014) buscou uma definição de que melhor se valesse a lei para atingir com maior eficácia os fins a que se destinou. Em análise acerca dos efeitos do Código Civil na regência das relações privadas e sua repercussão na jurisprudência, chegou à conclusão que levou ao desenvolvimento da ideia do "consumidor final imediato" - e daí cunhou o termo "finalismo aprofundado" -, a partir da interpretação do artigo $2^{\circ}$, caput do CDC em conjunto com o artigo 4ํㅜㄹ, inciso I do CDC, chegou ao entendimento da "vulnerabilidade" como requisito essencial para configuração da figura do consumidor, e não como uma simples decorrência natural.

Desta forma, exclui-se da proteção do CDC aquele suposto consumidor que não se encontra em situação de vulnerabilidade, v.g., uma grande empresa, e abarca, v.g., o pequeno empreendedor que, embora vise utilizar o bem adquirido na 


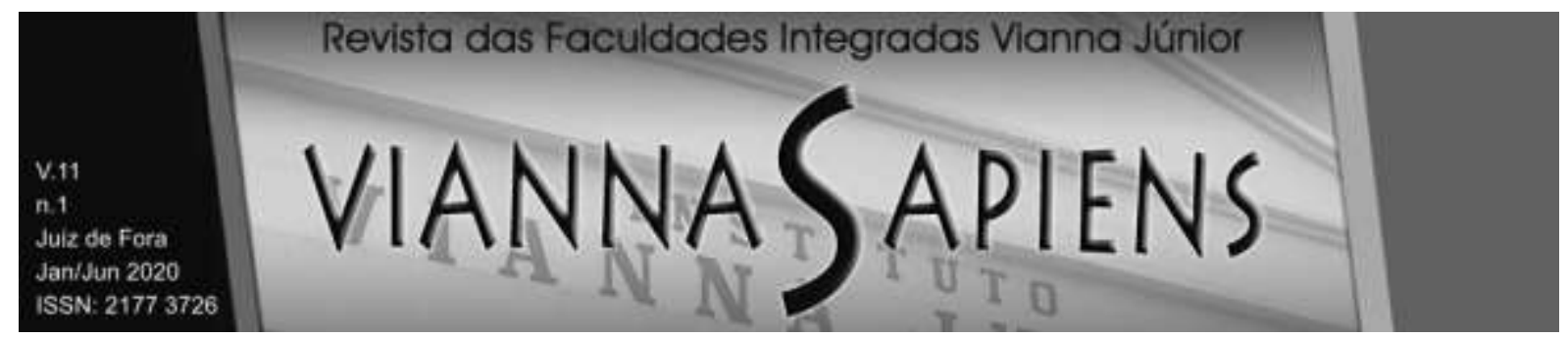

exploração de atividade econômica, pode ser entendido como vulnerável e, portanto, tutelado como consumidor. Dada a sua razoabilidade, tem sido esta a posição adotada pelo Superior Tribunal de Justiça (STJ) ${ }^{6}$.

A Lei no 8.078/1990 trouxe em certos dispositivos a figura do consumidor equiparado: a coletividade de pessoas que intervém de qualquer forma nas relações de consumo (artigo $2^{\circ}$, parágrafo único); a pessoa que não necessariamente tenha participado na relação de consumo, mas que tenha se tornado vítima de um fato danoso advindo da referida relação, também chamado bystander (artigo 17); e a que tenha sido exposta a certas práticas comerciais, v.g., oferta e publicidade (artigo 29). Trata-se de diferentes formas de ampliar a proteção jurídica conferida ao consumidor.

Resta explorar os elementos objetivos da relação de consumo, que são o produto e o serviço. Aquele significa, nos termos da Lei Consumerista, "qualquer bem, móvel ou imóvel, material ou imaterial", e acrescenta Tartuce (2018), que tenha sido disponibilizado nos meios de consumo.

O artigo 3, $2^{\circ}$ do CDC classifica como serviço qualquer atividade disponibilizada no mercado de consumo, mediante remuneração, ressalvados os casos que se submetam ao regime trabalhista (laboral). Apesar de a lei ser expressa ao apresentar a remuneração como requisito, caso o prestador ofereça serviço a título gratuito, mas dele obtenha vantagem indireta (gratuidade interessada), tal relação jurídica permanece caracterizada como de consumo, sem qualquer prejuízo ao consumidor (TARTUCE, 2018).

O exemplo mais clássico da hipótese tratada no parágrafo anterior é o de estabelecimentos comerciais que disponibilizam estacionamento gratuito, tornandose atraente para o cliente que deseja ali consumir. Nesses casos, a empresa proprietária do estacionamento é responsável pela reparação de danos ou furto de veículos no local, conforme enunciou o Superior Tribunal de Justiça (STJ) na Súmula

${ }^{6}$ STJ. REsp 1195642/RJ. Rel. Min. Nancy Andrighi, Terceira Turma. Data de julgamento: 13/11/2010. DJe 21/11/2012; STJ. AgRg no AREsp 837871/SP. Rel. Min. Marco Aurélio Bellizze, Terceira Turma. Data do julgamento: 26/04/2016. DJe 29/04/2016. 


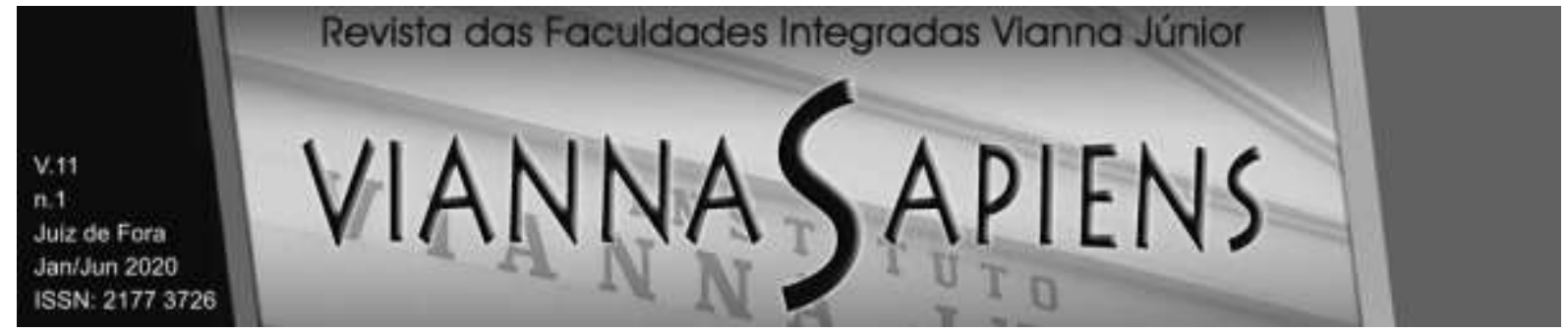

130. Neste caso, a empresa estaria sendo responsabilizada perante um consumidor direto de um serviço prestado mediante remuneração indireta.

\section{ABUSIVIDADE DO DESCUMPRIMENTO DA OFERTA NAS PLATAFORMAS DE MARKETPLACE}

A Lei Consumerista elenca nos incisos do seu artigo 39 um rol exemplificativo (numerus apertus) de práticas abusivas. Apesar de serem vedadas, o legislador deixou a cargo da doutrina e da jurisprudência a definição com mais exatidão e amplitude das diversas práticas que podem vir a caracterizar abusividade. Deste modo, é possível concluir que qualquer conduta que confronte o espírito e a finalidade do CDC deve ser entendida como prática abusiva. Esse entendimento retrata uma tentativa de ampliar as possibilidades de equilíbrio nas relações de consumo (TARTUCE, 2018).

Vale lembrar que o Código de Defesa do Consumidor é uma lei especial, no entanto, é possível aplicar às relações de consumo também o Código Civil, nos aspectos em que aquele não discipline de forma diversa - seguindo o que determina a Teoria do Diálogo das Fontes, que preconiza que as normas jurídicas não devem se excluir como corolário de pertencerem a ramos jurídicos diversos, e sim complementarem-se (MARQUES, 2014; GONÇALVES, 2018).

Feita tal introdução, é importante buscar no artigo 187 do Código Civil a ideia de abuso de direito: "também comete ato ilícito o titular de um direito que, ao exercêlo, excede manifestamente os limites impostos pelo seu fim econômico e social, pela boa-fé, ou pelos bons costumes". Evidentemente, o fornecedor que comete, na relação de consumo, qualquer ato que atente contra essas cláusulas gerais do Direito Privado, incidirá em prática abusiva, sujeitando-se às medidas de controle dispostas no Código de Defesa do Consumidor.

Não restam dúvidas de que nas relações de consumo firmadas na internet é possível a configuração de práticas abusivas, v.g., artigo 39, inciso III, CDC ("enviar 


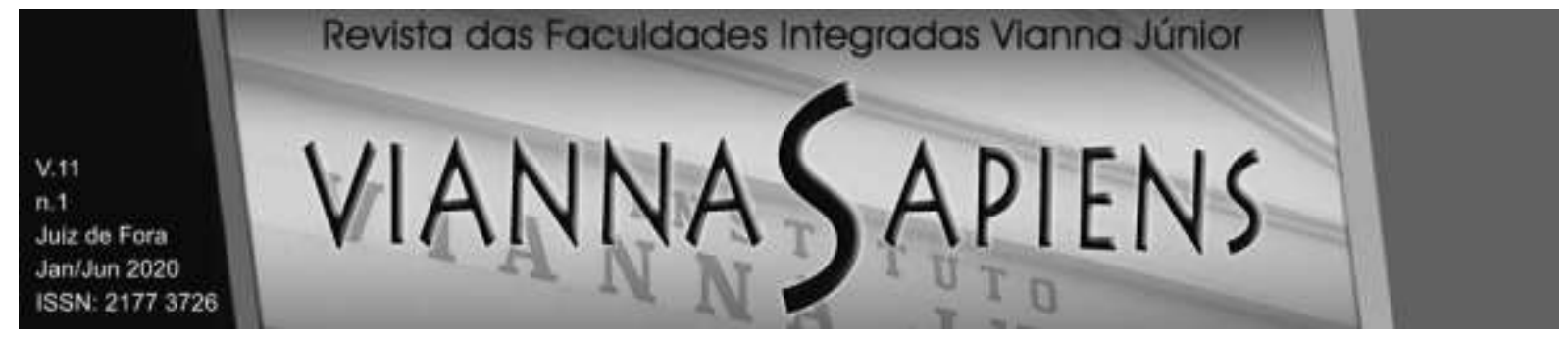

ou entregar ao consumidor, sem solicitação prévia, qualquer produto, ou fornecer qualquer serviço"). Todas as vedações instituídas no artigo 39 do CDC são plenamente aplicáveis aos fornecedores que atuam no comércio eletrônico - pois, como anteriormente mencionado, é possível a caracterização da relação de consumo que se efetue no meio virtual se presentes seus elementos -, não obstante, percebese que, em virtude de suas características únicas, a plataforma, enquanto fornecedora, é mais passível de cometer certas práticas em detrimento de outras.

Uma dessas características é o fato do martketplace ser acessível por qualquer pessoa, de qualquer lugar e a qualquer tempo, por meio da internet. Esta amplitude de exposição possibilita que certas práticas abusivas sejam cometidas, v.g., geopricing e o geo-blocking. Este ocorre quando o fornecedor deixa de oferecer produto ou serviço a morador de determinada região; e aquele quando preços diferentes são ofertados aos consumidores com base em sua localização geográfica (GUIMARÃES, 2019). Em ambos os casos, por óbvio, é necessário que esses comportamentos não sejam resultado naturalístico da atividade do fornecedor. Por exemplo, não deve ser punido o fornecedor que bloqueia oferta de serviço em território cuja legislação não permita a execução tal serviço; da mesma forma, se a localização do consumidor influi diretamente no custo do produto ou serviço, parece justo cobrar um preço distinto, mas proporcional, como no caso de fretes.

Outra característica das plataformas de marketplace é seu papel na relação de consumo, algumas vezes servindo de intermediadora do anúncio, do pagamento, e, por vezes, atua também na entrega dos produtos. Nesta esfera de funções, vê-se com frequência o descumprimento de ofertas, comumente por falta de estoque ou de disponibilidade para prestação de alguns serviços. Esta prática é expressamente proibida pela Lei Consumerista em seu artigo 30, que determina que a proposta feita por fornecedor, independentemente de ter sido por meio informacional ou publicitário, gera para ele a obrigação do cumprimento. A referida lei prevê, ainda, em seu artigo 35, que no caso de descumprimento o consumidor poderá escolher entre a exigência do cumprimento do contrato, quando possível, receber um produto semelhante ou 


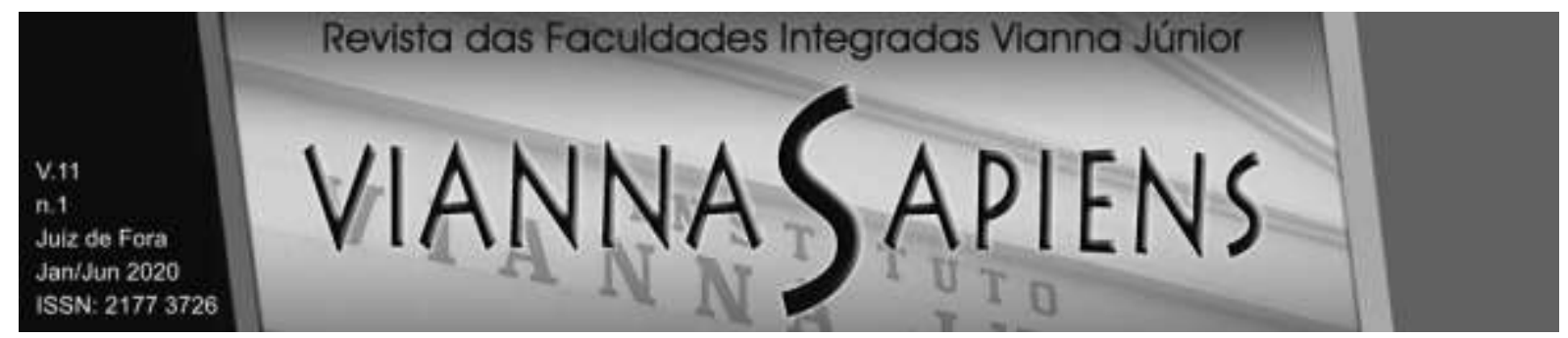

superior, ou receber de volta o preço pago, sem prejuízo da reparação por perdas e danos.

O termo "oferta" trazido pelo Código de Defesa do Consumidor deve ser entendido em sentido amplo, abrangendo toda forma de comunicação de caráter qualitativo feita por fornecedor acerca de seus produtos ou serviços com intuito de atrair o consumidor para a aquisição destes (TARTUCE, 2018).

É importante notar que essa oferta pode ser realizada de maneira individual, direcionada a um consumidor singular, ou de maneira a alcançar um grupo de consumidores, unidos por uma característica que os torna individualmente identificáveis. Nestes casos, diz-se que a oferta é determinada, por se conhecer com exatidão a quem se dirige. Por outro lado, a oferta pode ser indeterminada, quando direcionada ao público em geral, sem distinções, buscando seduzir e atrair futuros consumidores (ALVES, 2013). Apesar de ser possível a existência de ofertas determinadas dentro do marketplace, nestas plataformas elas costumam ser indeterminadas, sem discriminar a quem se dirige.

O artigo 31 do CDC traz algumas regras acerca do conteúdo dessa oferta, como a necessidade de clareza e precisão na transmissão das informações, e que estas devem ser feitas em língua portuguesa. Já o artigo 32 do CDC impõe ao fabricante ou importador o dever de disponibilizar no mercado peças de reposição para os produtos por eles ofertados, enquanto durar a fabricação ou importação, e por um período razoável após cessadas tais atividades. E o artigo 33 do CDC traz regras para a oferta realizada por telefone. O desrespeito às disposições previstas em quaisquer destes quatro artigos (30 a 33) pode resultar na configuração do descumprimento de oferta, estando essa inadimplência submetida ao previsto no artigo 35 do CDC (SILVA; FONSECA, 2018)

Levando-se em conta que a regra adotada pelo CDC, nos artigos 12, 14 e 17, é a da responsabilidade civil objetiva e solidária entre os fornecedores integrantes da cadeia de consumo, caso o fornecedor primário, que anuncia na plataforma, descumpra oferta, a reparação ao consumidor é de responsabilidade de ambos, e 


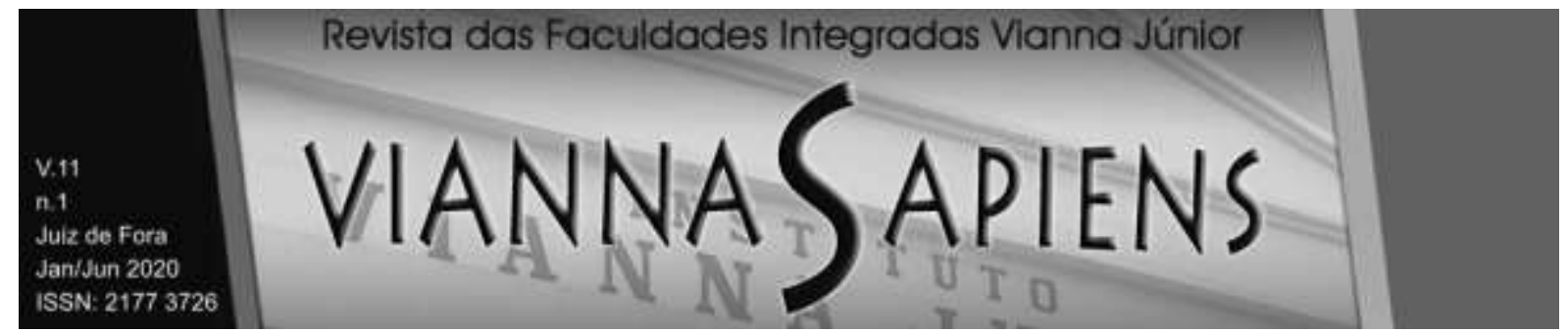

vice-versa. Portanto, é interessante que estes parceiros se fiscalizem entre si a fim de evitar prejuízos a qualquer das partes.

Para efetivar a proteção ao consumidor prevista em seu conteúdo, o Código de Defesa do Consumidor estabelece no Título IV o Sistema Nacional de Defesa do Consumidor (SNDC), regulado pelo Decreto $\mathrm{n}^{\circ}$ 2.181/1997, e composto por Procons, Ministério Público (MP), Defensoria Pública, Delegacias de Defesa do Consumidor, Juizados Especiais Cíveis e Organizações Civis de defesa do consumidor, que devem atuar juntos e em integração com a Secretaria Nacional do Consumidor (SENACON) para garantir os fins a que a lei se dirige. Questiona-se, portanto, como ocorre a atuação específica dos Procons no sentido de adotar medidas administrativas para proteger o consumidor, notadamente em relação aos casos de descumprimento de oferta veiculada nas plataformas de marketplace.

\section{ATUAÇÃO DOS PROCONS NOS CASOS DE DESCUMPRIMENTO DAS OFERTAS}

Impondo a Constituição Federal ao Poder Público, em mais de um dispositivo (artigo 5º, inciso XXII e artigo a170, inciso V), o dever geral de zelar pela defesa consumidor, é solar o entendimento de que não há inconstitucionalidade na tutela administrativa no âmbito das relações de consumo. Os órgãos públicos que atuam nesta seara não constituem entes policiais ou simplesmente fiscalizadores, manifestando-se primariamente como estrutura de amparo aos interesses individuais, coletivos e difusos dos consumidores, restando a fiscalização como atividade última desses, quase como se fosse função atípica (FILOMENO, 2018).

Os Procons possuem poder de polícia - que pode ser entendido como qualquer atividade da administração pública que regule, limitando ou disciplinando, interesse ou liberdade, ou prática de ato ou abstenção de fato, por razão de interesse público, nos termos do artigo 78 do Código Tributário Nacional - dentre suas funções 


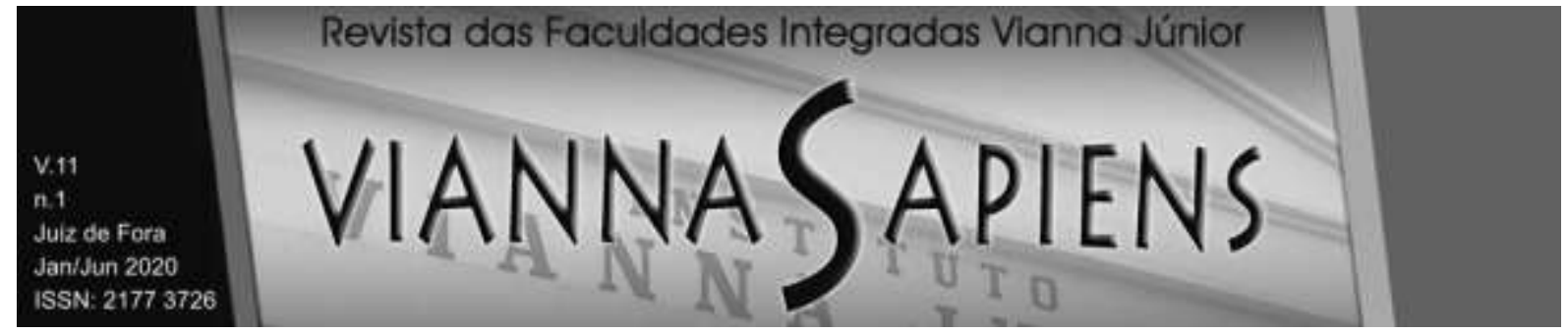

primárias, como normalmente estabelecido em seus atos regulamentares. Essa característica inclusive já foi reconhecida na jurisprudência:

É pacífico o entendimento no Superior Tribunal de Justiça segundo o qual a sanção administrativa prevista no artigo 57 do Código de Defesa do Consumidor funda-se no Poder de Polícia que o PROCON detém para aplicar multas relacionadas à transgressão dos preceitos da Lei n. 8.078/1990, independentemente da reclamação ser realizada por um único consumidor, por dez, cem ou milhares de consumidores. (STJ. Aglnt no REsp 1594667/MG, Rel. Ministra Regina Helena Costa, Primeira Turma. Data de julgamento: 04/08/2016. DJe 17/08/2016).

De acordo com o livro institucional do Procon-SP (2011), sua origem, em meados da década de 1970, se deu após a formação de um grupo no Poder Executivo Estadual que buscava identificar e tentar solucionar os principais problemas do Estado de São Paulo. Um dos problemas apontados foi em relação ao abastecimento de alimentos na Grande São Paulo, em especial à população de baixa renda, que pagava um valor acima da média por alimentos cuja procedência carecia de cuidados essenciais previstos nas leis sanitárias.

O atual Regulamento Geral do Procon-SP é recente, tendo sido publicado em maio de 2019, e traz como objetivo um dos objetivos da entidade elaborar e executar a Política Estadual de Defesa do Consumidor, remontando ao propósito do grupo pioneiro da década de 1970. Para alcançar tal objetivo, o Regulamento elenca, em seu artigo $3^{\circ}$, diversas atividades, como prestar informações aos consumidores sobre seus direitos, promover, no âmbito judicial, a defesa dos interesses individuais homogêneos, coletivos e difusos, além de "fiscalizar a execução das leis de defesa do consumidor e aplicar as respectivas sanções".

Então, além de genericamente autorizado pelo Código de Defesa do Consumidor, surge na sua regulamentação específica esse poder-dever de tutelar administrativamente os direitos do consumidor, sendo legitimado a impor sanções administrativas, dentre as previstas no artigo 56 da Lei Consumerista.

Sanção administrativa, como conceitua Medauar (2015), é um ato da administração pública que impõe a uma pessoa, física ou jurídica, uma obrigação, 


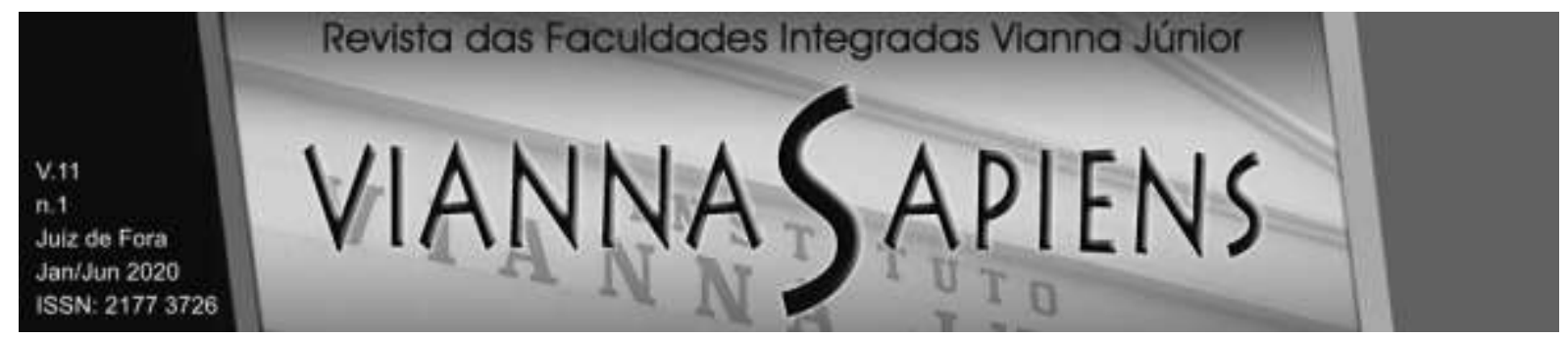

justificada em ato ou omissão de tal pessoa que viole preceitos legais, de forma que tal conduta seja configurada como infração administrativa, v.g., o cometimento de prática abusiva.

Devido ao proeminente papel da plataforma na divulgação, oferta e publicidade, além de intermediação no pagamento do objeto da relação de consumo, é relativamente mais comum que a esta se atribuam as práticas abusivas relacionadas à oferta de produtos e serviços. Dentre essas práticas encontram-se, por exemplo, o descumprimento pleno da oferta e o seu bloqueio injustificado em decorrência de características do consumidor como sua idade, gênero, religião, nacionalidade ou até mesmo localização geográfica.

Como mencionado anteriormente, na cadeia de consumo que se forma no marketplace, o comerciante que neste atua e a plataforma em si assumem papéis diferentes, mas para fins de responsabilização por descumprimento de oferta, por exemplo, ambos assumem o ônus em decorrência da responsabilidade prevista no artigo 30 do CDC, o qual determina que a oferta "obriga o fornecedor que a fizer veicular ou dela se utilizar e integra o contrato que vier a ser celebrado".

Entretanto, a aplicação das sanções previstas no artigo 56 do CDC pode apresentar relevância distinta a depender de quem as está recebendo. Enquanto comerciante e plataforma seriam igualmente atingidos, na medida de suas respectivas capacidades financeiras, por uma multa (inciso I), a apreensão e a inutilização do produto (inciso II e III, respectivamente) atingem muito mais o comerciante do que a plataforma, sendo esta atingida apenas indiretamente, por perder a possibilidade de lucro no intermédio das relações cujos produtos que foram alvo de sanção seriam objeto.

Em verdade, parece ser mais ampla a possibilidade de punição do comerciante, que pode ser atingido com impacto relevante por todas as sanções dispostas nos incisos I a XI do artigo 56 do CDC, enquanto a plataformas de marketplace somente se prejudicariam de maneira direta nas hipóteses de aplicação das sanções previstas nos incisos $\mathrm{VI}$ a XII, sendo este último o único caso em que a ela poderia ser 


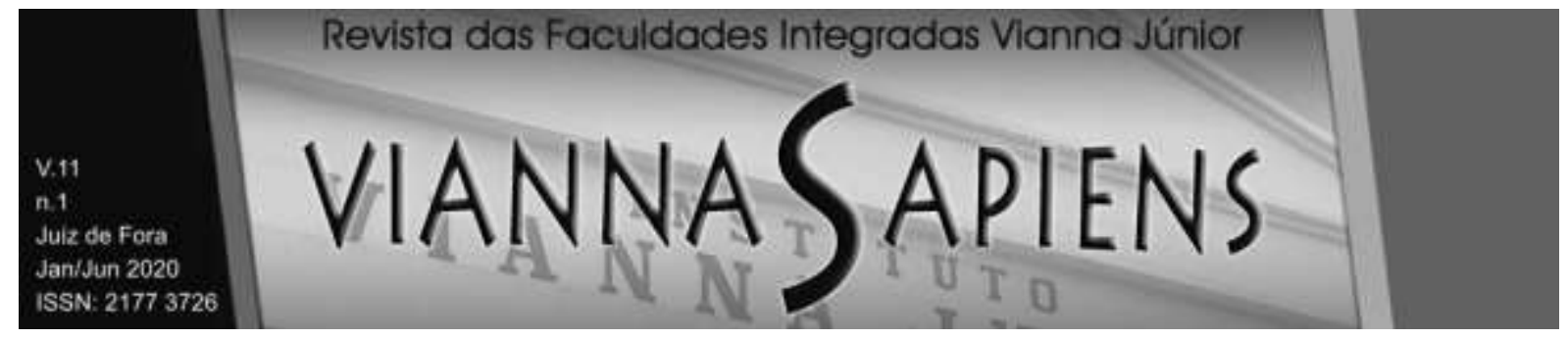

consideravelmente mais punida que o comerciante (artigo 56, inciso XII, CDC: "imposição de contrapropaganda").

Os Procons são instituições que se encontram espalhadas por todo o país, normalmente carregando a missão de elaborar e executar políticas locais de defesa do consumidor. Portanto, são incontáveis as ações que esses órgãos tomam todos os dias para alcançar seus objetivos. Não obstante, é possível visualizar alguns casos que bem se adequam ao tema proposto no presente trabalho.

Em março de 2012, o Procon-SP decidiu suspender temporariamente, para o Estado de São Paulo, os sites americanas.com.br, submarino.com.br, e shoptime.com.br - tendo todos operações no modelo marketplace -, da empresa $\mathrm{B} 2 \mathrm{~W}$, sendo os motivos principais a reclamação de diversos consumidores dessas plataformas que não receberam os produtos nelas adquiridos ou os receberam com vícios (defeitos).

Já em junho de 2014, o Procon-DF, ao analisar reclamações recebidas dos consumidores em decorrência de problemas nas relações de consumo efetuadas com a companhia de telecomunicação Vivo, constatou que esta cometia, entre outras práticas abusivas, o descumprimento de oferta, prestando serviços qualitativamente aquém do predeterminado no contrato. A sanção imposta em resposta às irregularidades foi a aplicação de multa.

\section{CONCLUSÃO}

Estando presentes os requisitos da relação de consumo, mesmo que firmada pelo meio eletrônico, há a submissão às regras do Código de Defesa do Consumidor. Portanto, observa-se que a licitude das condutas dos fornecedores que se utilizam dos marketplaces para a comercialização de seus produtos e serviços são delimitadas pelo que diz o Código em relação às práticas abusivas. 


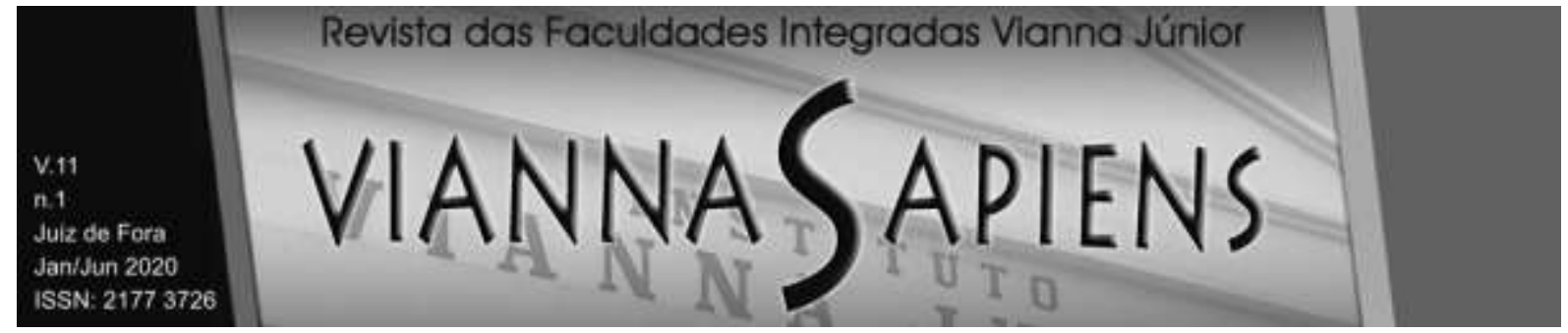

Constata-se que a oferta compõe parte considerável da atividade das plataformas de marketplace, e que o descumprimento dos termos estabelecidos nos artigos 30 a 35 do CDC para a realização da oferta caracteriza-se como prática abusiva. Além disso, também deve-se destacar que a regra da responsabilidade solidária e objetiva entre os fornecedores integrantes da cadeia de consumo impera nas relações estabelecidas no marketplace, sendo o vendedor responsabilizado pela oferta realizada pela plataforma, e vice-versa.

Sendo um dos principais órgãos responsáveis pela defesa dos direitos do consumidor, o Procon deve exercer suas funções e apurar as práticas abusivas relacionadas ao descumprimento da oferta, e, quando se constatar o cometimento do ilícito, utilizar do seu poder de polícia para impor aos responsáveis as sanções administrativas cabíveis dentre as elencadas no artigo 56 do CDC, dentre as quais é possível destacar a multa e a suspensão temporária da atividade.

Considerando que os números mostram uma expectativa de crescimento do modelo do marketplace na área do comércio eletrônico, e, consequentemente, o aumento do potencial de lesividade aos consumidores, mostra-se de máxima importância valorar a atuação dos Procons - e de outros órgãos - na tutela administrativa dos direitos do consumidor no tocante ao descumprimento de ofertas veiculadas neste tipo de ambiente virtual, o que pode, inclusive, reduzir o número de demandas judiciais sobre este tópico.

Em razão do fato de o descumprimento da oferta poder ser classificado como prática abusiva (considerando o rol do artigo 39 do CDC como exemplificativo), principalmente por não atender as determinações previstas no CDC, especialmente as que estão contidas nos artigos 30 a 35, os Procons, na qualidade de órgãos públicos que detêm poder de polícia, podem aplicar as sanções administrativas previstas no artigo 56 do Código de Defesa do Consumidor, inclusive responsabilizando solidariamente as plataformas de marketplace e os demais fornecedores que nela atuam. 


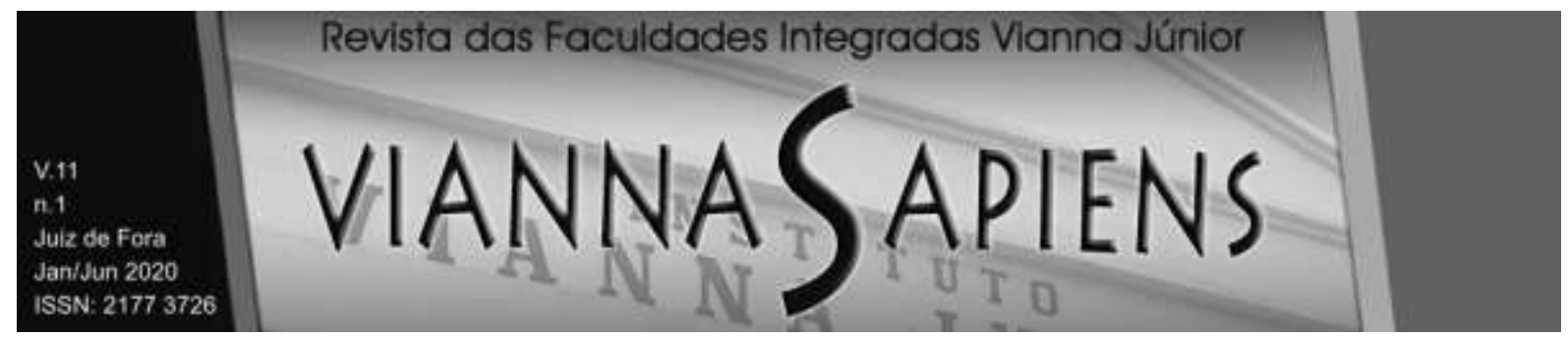

\section{REFERÊNCIAS}

ALVES, Fabrício Germano. Proteção constitucional do consumidor no âmbito da regulação publicitária. Natal: Espaço Internacional do Livro, 2013.

BRAGA NETTO, Felipe Peixoto. Manual de direito do consumidor: à luz da jurisprudência do STJ. 14.ed. ampl. e atual. Salvador: JusPodivm, 2019.

BRASIL. Conselho Nacional de Justiça. Justiça em números 2019: variáveis e indicadores do Poder Judiciário. Brasília: CNJ, 2019.

BRASIL. Constituição (1988). Constituição da República Federativa do Brasil. Brasília, DF: Senado Federal: Centro Gráfico, 1988.

BRASIL. Decreto no 2.181, de 20 de março de 1997. Dispõe sobre a organização do Sistema Nacional de Defesa do Consumidor - SNDC, estabelece as normas gerais de aplicação das sanções administrativas previstas na Lei no 8.078 , de 11 de setembro de 1990, revoga o Decreto № 861, de 9 julho de 1993, e dá outras providências. Brasília, 1997.

BRASIL. Lei ํㅜ 5.172, de 25 de outubro de 1966. Dispõe sobre o Sistema Tributário Nacional e institui normas gerais de direito tributário aplicáveis à União, Estados e Municípios. Código Tributário Nacional. Brasília, 1966.

BRASIL. Lei no 8.078 , de 11 de setembro de 1990. Dispõe sobre a proteção do consumidor e dá outras providências. Código de Defesa do Consumidor. Brasília, 1990.

BRASIL. Lei ㄲo 10.406, de 10 de janeiro de 202. Institui o Código Civil. Código Civil. Brasília, 2002.

BRASIL. Superior Tribunal de Justiça. Súmula no 130. A empresa responde, perante o cliente, pela reparação de dano ou furto de veículo ocorridos em seu estacionamento. Brasília, 1995. Disponível em:

https://ww2.stj.jus.br/docs_internet/revista/eletronica/stj-revista-sumulas2010_9_capSumula130.pdf. Acesso em: 29 mar. 2020. 


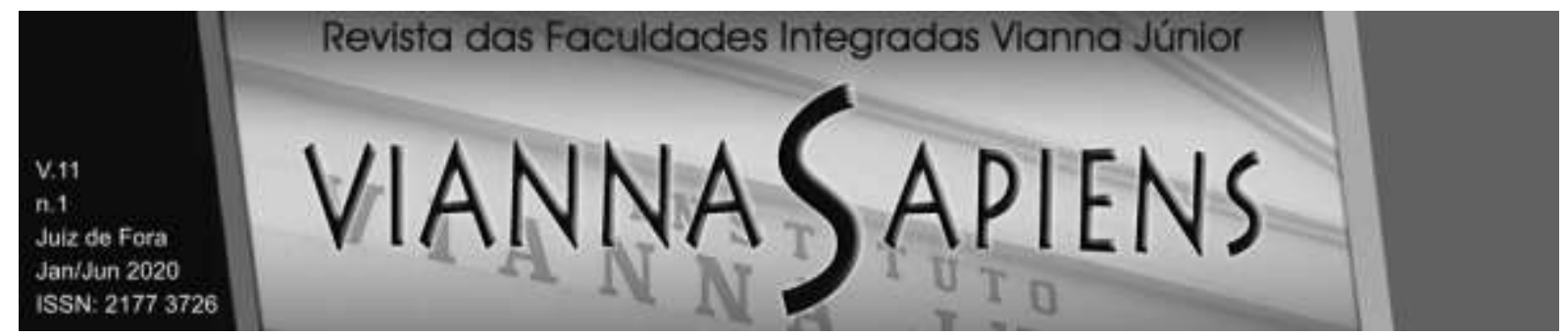

BENJAMIN, Antônio Herman V.; MARQUES, Claudia Lima; BESSA, Leonardo Roscoe. Manual de Direito do Consumidor. 6. ed. São Paulo: Revista dos Tribunais, 2014.

EBIT. Web Shoppers: Raio-X ano de 2004. 11. ed. 2005. Disponível em: https://pt.slideshare.net/romero.rodrigues/webshoppers-10-edio. Acesso em 29 mar. 2020.

EBIT. Web Shoppers. 24. ed. 2011. Disponível em: https://pt.slideshare.net/Startupi/relatrio-webshoppers-24. Acesso em 29 mar. 2020

EBIT. Web Shoppers. 39. ed. 2019. Disponível em:

http://www.medsobral.ufc.br/pdf/Webshoppers_39.pdf. Acesso em 29 mar. 2020.

FILOMENO, José Geraldo Brito. Manual de Direitos do Consumidor. 15. ed. São Paulo: Atlas. 2018.

GONÇALVES, Carlos Roberto. Direito Civil Brasileiro. 17. ed. São Paulo: Saraiva, 2019. v. 1.

GUIMARÃES, Marcelo Cesar. Geoblocking e geopricing: uma análise à luz da teoria do interesse público de Mike Feintuck. Revista de Direito, Estado e Telecomunicações, v. 11, nº 2, p. 87-106, outubro 2019.

IBGE. PNAD 2003. Pesquisa nacional por amostra de domicílios. Rio de Janeiro: IBGE, 2003.

IBGE. PNAD 2008. Pesquisa nacional por amostra de domicílios. Rio de Janeiro: IBGE, 2008.

IBGE. Síntese de indicadores sociais: uma análise das condições de vida da população brasileira: 2019. Rio de Janeiro: IBGE, 2019.

KLEE, Antônia Espíndola Longini. Comércio eletrônico. São Paulo: Revista dos Tribunais, 2014. 


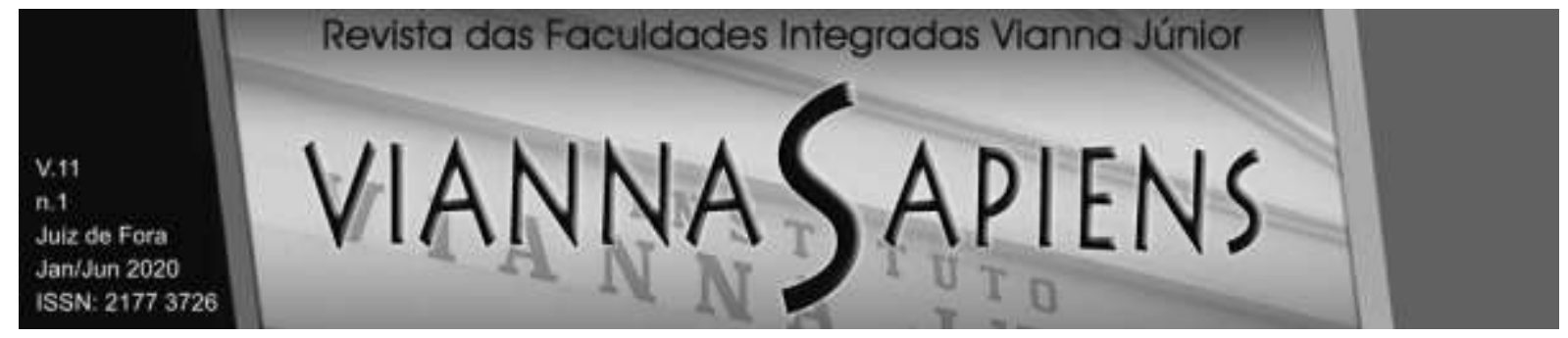

MEDAUAR, Odete. Sanção administrativa em geral e no Código de Defesa do Consumidor. In: FILOMENO, José Geraldo Brito. Tutela administrativa do consumidor: atuação dos PROCONs, legislação, doutrina e jurisprudência. São Paulo: Atlas, 2015.

MIRAGEM, Bruno. Curso de direito do consumidor. 8. ed. São Paulo: Revista dos Tribunais, 2019.

NUNES, Luiz Antônio Rizzatto. Curso de Direito de Consumidor. 11. ed. rev. e atual. São Paulo: Saraiva, 2017.

PROCON-DF notifica as empresas de telefonia Vivo e Claro. 2014. Disponível em: http://www.procon.df.gov.br/procon-df-aplica-multas-as-empresas-de-telefonia-vivoe-claro/. Acesso em 01 abr. 2020.

PROCON-SP suspende 3 sites de compra por problemas em serviço. 2012. Disponível em: http://g1.globo.com/sao-paulo/noticia/2012/03/procon-sp-suspende-3sites-de-compra-por-problemas-em-servico.html.

PROCON SP. 35 anos do Procon-SP. Fundação de Proteção e Defesa do Consumidor (Org.).

São Paulo: Imprensa Oficial do Estado de São Paulo, 2011.

REGULAMENTO GERAL DA FUNDAÇÃO PROCON/SP. Diário Oficial, Poder Executivo - Seção I, São Paulo: Imprensa Oficial, v. 129, n. 84, p.37-38, 04/05/2019. Disponível em:

http://www.imprensaoficial.com.br/DO/BuscaDO2001Documento_11_4.aspx?link=\% 2f2019\%2fexecutivo\%2520secao\%2520i\%2fmaio\%2f04\%2fpag_0037_00771f76eca 73d08b1d1155e584fcd58.pdf\&pagina=37\&data=04/05/2019\&caderno=Executivo\%20 I\&paginaordenacao=100037. Acesso em 29 mar. 2020.

SILVA, Evelin Pereira de Lima e; FONESCA, Renata Karen Gomes da. Recusar atendimento às demandas, na exata medida de suas disponibilidades de estoque, e, ainda, de conformidade com os usos e costumes. In: ALVES, Fabrício Germano; XAVIER, Yanko Marcius de Alencar; TRIGUEIRO, Leonardo Cartaxo (org.). Práticas abusivas previstas no Código de Defesa do Consumidor. Manaus: Elucidare, 2018. p. 35-51. (Série Direito das Relações de Consumo). 


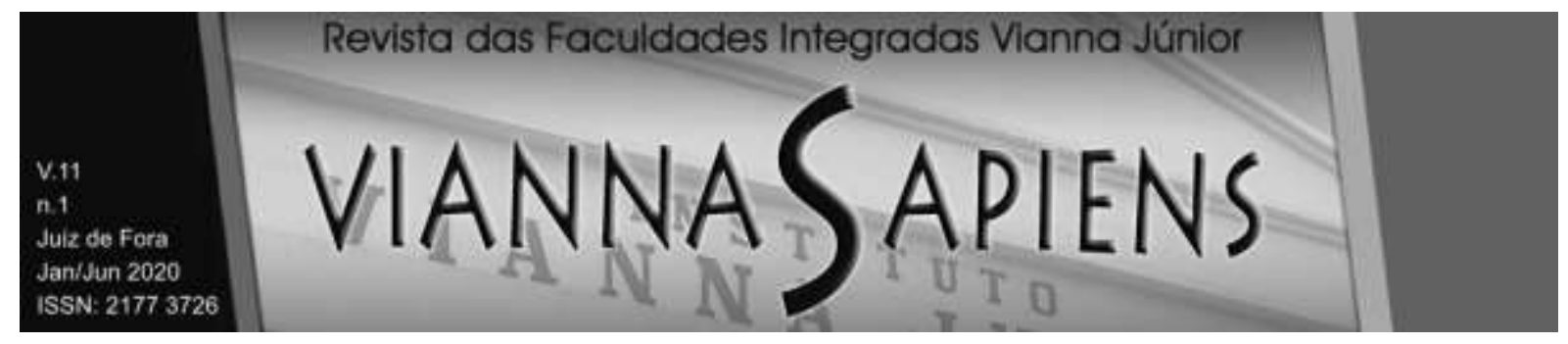

SILVA, Jorge Alberto Quadros de Carvalho. Código de Defesa do Consumidor Anotado e legislação complementar. 3. ed. São Paulo: Saraiva, 2003.

STARLING, Ana Paula. Marketplace e pequenos negócios: pesquisa aplicada ao ambiente do Elo7. 2018. 26 f. Monografia (Especialização) - Curso de Marketing Digital, Centro Universitário de Brasília, Brasília, 2018.

TARTUCE, Flávio; NEVES, Daniel Amorim Assumpção. Manual de Direito do Consumidor: direito material e processual. 7. ed. São Paulo: Método, 2018.

WANG, Shan; ARCHER, Norman. Electronic marketplace definition and classification: literature review and clarifications. Enterprise Information Systems, v. 1, p. 89-112, fev. 2007.

Recebido em 03/04/2020

Publicado em 12/05/2020 